\section{RELEVÂNCIA DA VALORIZAÇÃO DA ATENÇÃO À SAÚDE DO ADOLESCENTE NA REDE BÁSICÁ: UM RELATO DE EXPERIÊNCIA}

\section{RELEVANCE OF VALUATION OF TEENAGER HEALTH CARE IN THE BASIC NETWORK: AN EXPERIENCE REPORT}

\author{
Andreza Lima Silva ${ }^{1} /$ Luana Costa Ferreira $^{2, *}$ / \\ Paula Luísa Lima Melo de Barros $2 /$ \\ Raiza Magalhães Martins Rêgo Badaró ${ }^{2}$
} Tarcísio Viana Cardoso ${ }^{2}$

\section{INTRODUÇÃO}

Adolescência é o período de 10 e 19 anos de idade, sendo caraterizada pela busca da auto exploração psicológica para descobrir quem é e como se encaixará no mundo social em que vive. Uma fase do desenvolvimento em que os conceitos de si são plurais e estão em franca expansão. Esses conceitos bem-sucedidos ou fracassados ocorrem de maneira imprevisível, vulnerável e incertos, intervindo diretamente na sua trajetória ao longo da vida e também interferindo no cuidado de suas demandas de saúde exigindo novos modos de produzir saúde (NUNES, 2011).

A atenção integral à saúde dos adolescentes é um desafio para os profissionais de saúde, pois se trata de um grupo social em fase de importantes transformações psicobiológicas e um momento distinto no processo de desenvolvimento humano articuladas a um envolvimento social (BRASIL, 2017).

Nesse sentido, o Ministério da Saúde (MS) visa inserir adolescentes na Atenção Básica (AB)/ Estratégia de Saúde da Família (ESF), não apenas na perspectiva de serem alvo das ações de saúde, mas incluí-los como protagonistas sociais. No Brasil, há um intenso movimento e ações com vistas a integrar educação e saúde através do Programa Saúde na Escola (PSE), contribuindo para além da formação integral dos jovens por meio de ações de prevenção, promoção e atenção à saúde, nos espaços das escolas e/ou nas unidades de saúde (FONTANELE et al, 2017).

\section{RESUMO}

O presente estudo objetiva analisar a relevância da valorização da atenção à saúde do adolescente na rede básica, ao relatar a experiência vivenciada na implantação de um grupo de educação em saúde para esse faixa etária. Trata-se de um relato de experiência de um Projeto de Educação em Saúde, utilizando a metodologia de "Roda de Conversa", a fim de verificar a percepção do adolescente com faixa etária de 11 a 15 anos, sobre si e do seu papel da sociedade para posteriormente montar uma estratégia de subsidiar a atenção voltada a saúde dessa população. Durante as dinâmica ofertadas, observou-se a vontade dos adolescentes de entender temas relacionados à saúde e aos aspectos sociais. O desejo de proporcionar atividades que deixem esse grupo mais próximo das ações preventivas foi mencionado no momento, sendo esta, a próxima etapa desse projeto. Apesar da ESF ser a porta de entrada da saúde primária, ainda não há ações de participação ativa dos adolescentes, e esta experiência demonstra que é possível incluir esse público neste processo, para que assim tenhamos a efetivação da saúde baseado nos princípios do SUS de universalidade, equidade e integralidade.

Palavras-chave: Adolescência. Grupos. Promoção da Saúde.

\section{ABSTRACT}

This study aims to analyze the relevance of valuing adolescent health care in the basic network, when reporting the experience of implementing a health education group for this age group. It is an experience report of a Health Education Project, using the "Conversation Wheel" methodology, in order to verify the perception of the adolescent aged 11 to 15 years, about themselves and their role in the society to later put together a strategy to subsidize the health care of this population. During the dynamics offered, the adolescents' willingness to understand topics related to health and social aspects was observed. The desire to provide activities that bring this group closer to preventive actions was mentioned at the time, this being the next stage of this project. Although the FHS is the gateway to primary health, there are still no active participation actions by adolescents, and this experience demonstrates that it is possible to include this audience in this process, so that we have the effectiveness of health based on SUS principles of universality, equity and integrality.

Keywords: Adolescence. Groups. Health Promotion.

Submetido em: 08 de nov. 2019

Aceito em: 14 de fev. 2020

${ }^{1}$ Secretaria Municipal de Saúde, Guanambi, Bahia - Brasil

${ }^{2}$ Centro Universitário FG - UNIFG, Guanambi, Bahia - Brasil

*E-mail para correspondência: luanacostaferreira1 @ outlook.com

Rev. ComCiência - jun. 2020, vol. 5, no. 6, p. 79-81 / doi: 10.36112/issn2595-1890.v5.i6.p79-81 
Diversos estudos mostram que o PSE favorece o fortalecimento de articulações entre saúde e educação o que vem sendo apontado em vários estudos. Entretanto, observam-se lacunas na inserção das ações de promoção no planejamento, seja na educação ou na saúde, tendo em vista a dificuldade em atrair os adolescentes para a escuta. É válido salientar, contudo, que apesar dos obstáculos envolvidos no desenvolvimento de ações voltadas para os adolescentes é possível estabelecer rotina para o curso das atividades propostas com inovação e atendendo aos preceitos de promoção de saúde (NUNES, 2011).

Corrobora com essa afirmação Macêdo, 2013, afirmando que as intervenções grupais têm sido apontadas nessas publicações como um poderoso veículo de comunicação e promoção da mudança de comportamentos e porque possibilitam a emergência de questões individuais que podem ser discutidas e refletidas também na coletividade.

Tendo em vista que as ações envolvendo adolescentes e a intersetorialidade (ESF/Escola) ainda são incipientes e sabendo da importância desse grupo populacional, este estudo objetiva relatar a experiência vivenciada na implantação de um grupo de educação em saúde realizado para adolescentes por meio da percepção da relevância na valorização da atenção à saúde do adolescente na rede básica.

\section{MATERIAIS E MÉTODOS}

Trata-se de um relato de experiência de um Projeto de Educação em Saúde para adolescentes no âmbito PSE. Para Fontanella, 2011, o relato de experiência tem como principal objetivo dar uma orientação geral ao autor com relação à estruturação de relatos de experiência profissional. A relevância de um relato de experiência está na pertinência e importância dos problemas que neles expõem, assim como o nível de generalização na aplicação de procedimentos ou de resultados da intervenção em outras situações similares, ou seja, serve como uma colaboração à práxis metodológica da área a qual pertence.

Seguindo o caminho metodológico, delineou-se a implantação da atividade, a partir de demanda da Secretaria Municipal de Saúde de Guanambi em se criar a rotina de trabalho com adolescentes na $\mathrm{AB}$, observou-se um desafio em trazer adolescentes para a unidade de saúde, porém a primeira estratégia utilizada pelo grupo de trabalho foi a de buscar o acesso e a sensibilização dos profissionais da rede de atendimento e ensino envolvidos no PSE; por meio de reuniões com a Equipe de Saúde da Família (ESF), Núcleo Ampliado de Saúde da Família (NASF-AB), além de contato intersetorial com a escola emergiram sugestões em realizar atividade de PSE extramuros à escola, transcendendo para a estrutura física da USF.

Após este processo, foram elencadas as reais necessidades por meio de uma proposta de intervenção de cuidado. Essa proposta foi desenvolvida em uma articulação entre a coordenação da unidade e a escola pertencente ao município de Guanambi, localizado na microrregião do alto sertão baiano estado da Bahia. Participaram do grupo, 60 adolescentes que frequentavam a escola do território de cobertura da ESF, sendo estes, do $8^{\circ}$ e $9^{\circ}$ ano. A faixa etária dos adolescentes variou de 11 a 15 anos. As ações propostas e as intervenções foram desenvolvidas tendo como cenário ESF, com embasamento no PSE.
O período de atividades do grupo aconteceu entre os meses de Fevereiro e Abril de 2019, no início do semestre letivo, com periodicidade de um dia da semana, com encontro distribuído em dois horários correspondentes à uma hora aula. Para operacionalizar a prática do grupo e para incentivar o acesso dos adolescentes na ESF, os mesmos, acompanhados da professora da disciplina de Sociologia, foram acolhidos pela equipe da unidade de saúde da família.

O método da abordagem foi a "Roda de Conversa" conduzida pela Coordenadora da Unidade de Saúde e por Profissional de Psicologia do NASF-AB. Os adolescentes foram previamente orientados à acompanhar um filme sobre a temática "Sentimentos do Adolescentes", sendo entregues aos participantes placas com imagens dos personagens do filme, as quais assemelhavam-se a sentimentos de raiva, medo, tristeza, nojo e alegria, dessa forma, foi solicitado que cada integrante segurasse a placa correspondente ao seu sentimento naquele momento; Os sentimentos escolhidos foram relatados e ao final foi proporcionado um momento de reflexão conjunta e compartilhamento de sentimentos mútuos na coletividade.

Como se trata de um relato de experiência, não foi abordado nenhum aspecto de pesquisa que envolveu seres humanos e por isso não apresenta Parecer de Comitê de Ética em Pesquisa.

\section{RESULTADOS E DISCUSSÃO}

No encontro dos grupos os sujeitos foram instigados a desenvolver um conceito de si e alterações emocionais relacionadas aos sentimentos. Inicialmente, o grupo era composto por indivíduos, na grande maioria, sem 
interesse na intervenção proposta, com conversas secundárias e descrentes, mas no decorrer das atividades, foram aumentando a participação e confiança, e aos poucos houve uma clara desmistificação do conceito préestabelecido e ainda em construção de saúde e adolescentes, já que o acesso dos mesmos praticamente se resume à momentos não preventivos e práticas biomédicas, o que diverge da política de saúde do adolescente.

Durante a dinâmica das emoções foram observadas diversas manifestações de relacionados aos sentimentos. Considerando a produção de saberes gerada durante o grupo, os adolescentes sugeriram por demanda livre opções de novos temas para serem abordados em novos encontros, foram temas sugeridos: bullyng, ansiedade e suicídio.

Nota-se que os resultados foram maiores que os esperados já que foi possível despertar nos adolescentes a vontade de entender temas relacionados à saúde e aos aspectos sociais. Por fim, foi discutido sobre a importância da valorização pessoal, relação interpessoal, bem estar físico e mental para uma melhor qualidade de vida, assim como o aumento da autoestima. Neste momento a proposta de valorizar e criar estratégias para inclusão desses jovens na atenção primária tomou forma e o desejo de proporcionar atividades que deixem esse grupo mais próximo das ações preventivas foi mencionado no momento, sendo este a próxima etapa desse projeto.

\section{CONCLUSÃO}

É possível concluir que a implantação do grupo de adolescentes é de grande importância já que foi possível gerar uma troca de saberes e experiências entre os envolvidos no grupo, além de ter sido uma oportunidade de destacar sentimentos mútuos.

Sabe-se que a ESF, apesar de ser a porta de entrada do SUS, ainda não efetivou ações atrativas para a participação ativa dos adolescentes no processo da saúde primária, e esta experiência demonstra que é possível construir boa relação entre a educação e saúde, e sobretudo, incluir os adolescentes neste processo para que assim tenhamos a efetivação da promoção, prevenção e participação destes importantes protagonistas do seu cuidado.

\section{REFERÊNCIAS}

BRASIL, E.G.M et al. Promoção da saúde de adolescentes e Programa Saúde na Escola: complexidade na articulação saúde e educação. Rev Esc Enferm USP, 2017. Disponível em: <http://www.scielo.br/pdf/reeusp/v51/ 1980-220X-reeusp-S1980-

220X2016039303276.pdf>. Acesso em 25 de março de 2019.

FONTENELE et al. Construção e validação participativa do modelo lógico do Programa Saúde na Escola, Revista Saúde debate, 2017. Disponível em: <https://www.scielosp.org/article/sdeb/ 2017.v41nspe/167-179/>. Acesso em 10 de agosto de 2019.

\section{MACEDO, E.O.S; CONCEICAO,}

M.I.G. Ações em grupo voltadas à promoção da saúde de adolescentes. Rev. bras. crescimento desenvolv. hum., São Paulo, v. 23, n. 2, p. 222-230, 2013. Disponível em $<$ http://pepsic.bvsalud.org/scielo.php?s cript $=$ sci_arttext\&pid=S0104$12822013000200016 \& \operatorname{lng}=$ pt\&nrm $=$ is o>. Acesso em 12 out. 2019.

MACHADO, M.F.A.S et al . Programa saúde na escola: estratégia promotora de saúde na atenção básica no Brasil. J. Hum. Growth Dev., São Paulo , v. 25, n. 3, p. 307-312, 2015, Disponível em <http://pepsic.bvsalud.org/scielo.php?s cript $=$ sci_arttext\&pid=S0104-
$12822015000300009 \& \operatorname{lng}=$ pt\&nrm=is o>. Acesso em 12 out. 2019. http://dx.doi.org/10.7322/jhgd.96709.

NUNES, A.C.P. Conceito de SI e Alterações Emocionais em Adolescentes [dissertação] [Internet]. Lisboa: Universidade de Lisboa - UL; 2011. Disponível em:

<http://repositorio.ul.pt/bitstream/1045 1/4872/1/ulfpie039643_tm.pdf >.

Acesso em 10 de março de 2019.

SAMPAIO, J et al. Limites e potencialidades das rodas de conversa no cuidado em saúde: Uma experiência com jovens no sertão pernambucano. Revista Interface Paraíba, p. 1299-1312, 2014. Disponível em: <http://www.scielo.br/pdf/icse/v18s2/1 807-5762-icse-18-s2-1299.pdf $>$. Acesso em 15 de agosto de 2019. 